\title{
Intestinal transplantation in children with chronic intestinal pseudo-obstruction
}

\author{
L Sigurdsson, J Reyes, S A Kocoshis, G Mazariegos, K M Abu-Elmagd, J Bueno, \\ C Di Lorenzo
}

$S$ A Kocoshis

C Di Lorenzo

The Thomas Starzl Transplantation Institute, Department of Surgery, University of Pittsburgh,

Pittsburgh,

Pennsylvania, USA

J Reyes

G Mazariegos

K M Abu-Elmagd

J Bueno

Correspondence to:

Dr Sigurdsson.

Accepted for publication 27 April 1999

Keywords: intestinal transplantation; small bowel transplantation; children; chronic intestinal pseudo-obstruction; small bowel motility; total parenteral nutrition

Chronic intestinal pseudo-obstruction (CIPO) is one of the disorders causing intestinal failure in children. Pseudo-obstruction refers to a heterogeneous group of disorders that are characterised by signs and symptoms of intestinal obstruction in the absence of mechanical evidence of obstruction. ${ }^{1}$ It is caused by ineffective intestinal contractions. Most cases of childhood CIPO are congenital and primary. Every part of the intestinal tract and other hollow viscera such as urinary bladder may also be

\begin{abstract}
Department of Paediatric Gastroenterology, Children's Hospital of Pittsburgh, 3705 Fifth Avenue, Pittsburgh, PA 15213-2583, USA L Sigurdsson

Abstract

Background-Children with chronic intestinal pseudo-obstruction (CIPO) often require total parenteral nutrition (TPN) which puts them at risk of liver failure and recurrent line infections. Intestinal transplantation has become a therapeutic option for TPN dependent children with intestinal failure who are failing management with TPN.

Aims-To investigate the outcome of children with CIPO referred for intestinal transplantation.

Methods-A retrospective review was carried out of records and diagnostic studies from 27 patients with CIPO referred for intestinal transplantation.

Results-Five children were not listed for transplantation: two because of parental decision, two because of suspicion of Munchausen syndrome by proxy, and one because he tolerated enteral nutrition. Six are still TPN dependent and awaiting transplantation. Eight children died awaiting transplantation. Eight children underwent transplantation. Three died (two months, seven months, and four years after transplant). Five children are alive with a median follow up of 2.6 years (range two months to six years). All transplanted children were able to tolerate full enteral feedings. The postoperative course was complicated by dumping syndrome, Munchausen syndrome by proxy, narcotic withdrawal, and uncovering of achalasia. Conclusion-Intestinal transplantation may be a life saving procedure in children with CIPO. Early referral and thorough pretransplant evaluation are keys to successful transplantation.

(Gut 1999;45:570-574)
\end{abstract}

affected. $^{23}$ Antroduodenal manometry is invariably abnormal in children with $\mathrm{CIPO}^{4-6}$ and suggests either abnormal smooth muscle (myopathic form) or neuronal (neuropathic form) function. Children with CIPO often have an adequate length of bowel but dysmotility produces vomiting, abdominal distension, and constipation, hampering nutritional intake. Morbidity and mortality of CIPO are mostly related to the effects of long term use of total parenteral nutrition (TPN).

The prognosis in CIPO varies greatly, with as many as one third of children dying in the first year of life. ${ }^{2}$ The high mortality is partly due to the association with other abnormalities. $\mathrm{Pa}-$ tients with urinary bladder neuromuscular disease are at risk of urinary tract infections. Malrotation has been reported in $40-70 \%$ of children with $\mathrm{CIPO},{ }^{2}{ }^{3}$ increasing the risk of volvulus and bowel ischaemia. When immunodeficiencies are associated with CIPO, there is a higher risk of sepsis and other life threatening infections. ${ }^{8}$ Some CIPO patients are able to tolerate enteral feedings, through gastrostomies or jejunostomies, which allow slow infusion of nutrients; others are TPN dependent for life. ${ }^{9}$

Intestinal transplantation has become a life saving therapeutic option for children with intestinal failure who are suffering complications of TPN. The vast majority of children undergoing intestinal transplant suffer from short bowel syndrome. ${ }^{10}{ }^{11}$ Chronic intestinal pseudo-obstruction, being a functional rather than an anatomical cause of intestinal failure, has unique characteristics which make pre- and postoperative management more complicated. In this paper, we report the outcome of children with CIPO referred for intestinal transplantation.

\section{Patients and methods}

From the list of 204 children with intestinal failure referred to the Children's Hospital of Pittsburgh for intestinal transplant evaluation between 1989 and 1997 we identified 27 patients (14 girls, 13 boys; aged 1-19 years, median 7 years) referred with the diagnosis of CIPO. Transplantation evaluation included barium studies of the gastrointestinal tract to establish length and anatomy of the intestine. Antroduodenal, colonic, and anorectal manometries were performed or previous studies reviewed to confirm diagnosis and what organs were involved. Ultrasound of the kidneys and a

Abbreviations used in this paper: $\mathrm{CIPO}$, chronic intestinal pseudo-obstruction; TPN, total parenteral nutrition; AChE, acetylcholinesterase. 
Table 1 Characteristics of patients with chronic intestinal pseudo-obstruction (CIPO) referred for transplant evaluation

\begin{tabular}{|c|c|c|c|c|c|c|c|}
\hline Patient & $\begin{array}{l}\text { Age (y) at } \\
\text { evaluation }\end{array}$ & $\begin{array}{l}\text { Age (y) at } \\
\text { presentation }\end{array}$ & $\begin{array}{l}\text { Type of CIPO by } \\
\text { manometry }\end{array}$ & Organs involved & Reason for referral & $\begin{array}{l}\text { Bilirubin }(\mu m o l / l) \\
\text { at evaluation }\end{array}$ & Outcome \\
\hline 1 & 11 & $10 \mathrm{y}$ & Neuropathic & SB & Liver disease & 7.2 & Transplant \\
\hline 2 & 4 & Birth & Myopathic & $\mathrm{St} / \mathrm{SB} / \mathrm{Col} / \mathrm{Bl}$ & Liver disease & 468 & Transplant \\
\hline 3 & 10 & $2 \mathrm{y}$ & Neuropathic & $\mathrm{St} / \mathrm{SB}$ & Infection/pain & 11 & Transplant \\
\hline 4 & 2 & Birth & Myopathic & $\mathrm{St} / \mathrm{SB} / \mathrm{Col} / \mathrm{Bl}$ & Infection & 13 & Transplant \\
\hline 5 & 2 & Birth & Myopathic & $\mathrm{St} / \mathrm{SB} / \mathrm{Col} / \mathrm{Bl}$ & Liver disease & 432 & Transplant \\
\hline 6 & 2 & Birth & Neuropathic & SB & Liver disease/infection & 13 & Transplant \\
\hline 7 & 17 & $10 \mathrm{y}$ & Neuropathic & $\mathrm{O} / \mathrm{St} / \mathrm{SB} / \mathrm{Col} / \mathrm{Bl}$ & Pain & 7 & Transplant \\
\hline 8 & 10 & Birth & Neuropathic & $\mathrm{St} / \mathrm{SB} / \mathrm{Col}$ & Liver disease/infection & 11 & Transplant \\
\hline 9 & 7 & Birth & Neuropathic & $\mathrm{SB} / \mathrm{Bl}$ & Pain/infection & 378 & Died \\
\hline 10 & 16 & Birth & Myopathic & $\mathrm{St} / \mathrm{SB} / \mathrm{Col} / \mathrm{Bl}$ & Liver disease & 216 & Died \\
\hline 11 & 7 & $1 \mathrm{y}$ & Myopathic & $\mathrm{O} / \mathrm{St} / \mathrm{SB} / \mathrm{Col} / \mathrm{Bl}$ & Infection & 7 & Alive/TPN \\
\hline 12 & 6 & Birth & Neuropathic & $\mathrm{SB} / \mathrm{Col}$ & Liver disease/infection & 133 & Alive/TPN \\
\hline 13 & 8 & $5 \mathrm{y}$ & Myopathic & SB & Infection & 9 & Alive/TPN \\
\hline 14 & 1 & Birth & Myopathic & $\mathrm{St} / \mathrm{SB} / \mathrm{Col} / \mathrm{Bl}$ & Vascular access & 9 & Alive/TPN \\
\hline 15 & 3 & $2 \mathrm{~m}$ & Myopathic & $\mathrm{St} / \mathrm{SB} / \mathrm{Col} / \mathrm{Bl}$ & Liver disease & 220 & Died \\
\hline 16 & 7 & Birth & Neuropathic & SB & Liver disease & 4 & Not listed \\
\hline 17 & 4 & Birth & Myopathic & $\mathrm{St} / \mathrm{SB} / \mathrm{Col} / \mathrm{Bl}$ & Liver disease & 720 & Died \\
\hline 18 & 7 & Birth & Myopathic & $\mathrm{St} / \mathrm{SB} / \mathrm{Col} / \mathrm{Bl}$ & Infection & 329 & Died \\
\hline 19 & 16 & Birth & Neuropathic & SB & Infection & 9 & Alive off TPN \\
\hline 20 & 1 & Birth & Myopathic & $\mathrm{St} / \mathrm{SB} / \mathrm{Col}$ & Liver disease & 216 & Died \\
\hline 21 & 4 & Birth & Myopathic & $\mathrm{St} / \mathrm{SB} / \mathrm{Col}$ & Liver disease & 180 & Died \\
\hline 22 & 8 & Birth & Myopathic & $\mathrm{St} / \mathrm{SB} / \mathrm{Col}$ & Infection & 7 & Alive/TPN \\
\hline 23 & 3 & $4 \mathrm{~m}$ & Myopathic & $\mathrm{SB} / \mathrm{Col}$ & Vascular access & 14 & Alive/TPN \\
\hline 24 & 3 & $6 \mathrm{~m}$ & Neuropathic & $\mathrm{St} / \mathrm{SB} / \mathrm{Col}$ & Liver disease & 216 & Died \\
\hline 25 & 4.5 & $1 \mathrm{y}$ & Normal & & Pain & 11 & Not listed \\
\hline 26 & 11 & $5 \mathrm{y}$ & Normal & & Pain & 18 & Not listed \\
\hline 27 & 2 & Birth & Neuropathic & $\mathrm{St} / \mathrm{SB} / \mathrm{Col}$ & Infection & 18 & Not listed \\
\hline
\end{tabular}

SB, small bowel; St, stomach; Col, colon; Bl, bladder; O, oesophagus; TPN, total parenteral nutrition.

urological evaluation were obtained in all children in order to evaluate the urinary tract for possible megacystis. Liver biopsy was performed in those with biochemical evidence of liver injury or abnormal liver imaging studies in order to judge whether the liver needed to be transplanted. Children with evidence of irreversible synthetic liver injury (persistent coagulopathy, hyperbilirubinaemia, hypoalbuminaemia, and hyperammonaemia) were deemed to need the liver as part of the transplantation based on clinical evidence without a need for biopsy.

Manometry studies were suggestive of myopathy in 14 patients and neuropathy in 11 . Two children were found to have normal antroduodenal and colon manometries. Their clinical histories were suggestive of Munchausen syndrome by proxy and they were not considered candidates for transplantation. The parents of two children with neuropathy elected not to have their child listed for transplantation. Eight children (aged 3-17 years) died awaiting transplantation; the cause of death was multiorgan failure secondary to liver disease in five, gastrointestinal bleeding in one, sepsis in one, and unknown in another.

Every child with direct bilirubinaemia $(>150$ $\mu \mathrm{mol} / \mathrm{l}$ ) who was not transplanted died (table 1). Six patients are TPN dependent and are awaiting transplant. One patient was successfully weaned off TPN and is now on enteral feeding and no longer listed for transplantation. Eight patients underwent transplantation, seven at the Thomas E Starzl Transplantation Institute; one was transplanted at another centre but has since been evaluated again by our centre, and is therefore included in the analysis. Table 1 summarises the patients' characteristics.

We have followed eight patients (five girls) with a median age of 4.8 years (range 23

Table 2 Course and outcome of patients who underwent transplantation (patients 1-8 from table 1)

\begin{tabular}{|c|c|c|c|c|c|c|c|c|}
\hline & \multicolumn{8}{|l|}{ Patient } \\
\hline & 1 & 2 & 3 & 4 & 5 & 6 & 7 & 8 \\
\hline Sex & Female & Female & Female & Male & Female & Male & Female & Female \\
\hline Manometry & Neuropathic & Myopathic & Neuropathic & Myopathic & Myopathic & Neuropathic & Neuropathic & Neuropathic \\
\hline Pathology & $\begin{array}{l}\text { Increased } \\
\text { AChE+ fibres } \\
\text { in SB mucosa }\end{array}$ & $\begin{array}{l}\text { Atrophy and } \\
\text { vaculoations of } \\
\text { muscle }\end{array}$ & $\begin{array}{l}\text { AChE+ fibres } \\
\text { in SB mucosa }\end{array}$ & $\begin{array}{l}\text { No } \\
\text { pathological } \\
\text { changes }\end{array}$ & $\begin{array}{l}\text { No } \\
\text { pathological } \\
\text { changes }\end{array}$ & $\begin{array}{l}\text { Neuronal } \\
\text { dysplasia }\end{array}$ & $\begin{array}{l}\text { No ganglia, } \\
\text { antiganglia } \\
\text { antibodies }\end{array}$ & $\begin{array}{l}\text { Hypertrophic } \\
\text { AChE+ fibres }\end{array}$ \\
\hline Age at transplant & $11 \mathrm{y}$ & $4.5 \mathrm{y}$ & $11 \mathrm{y}$ & $5 y$ & $23 \mathrm{~m}$ & $4.5 \mathrm{y}$ & $18 \mathrm{y}$ & $11 \mathrm{y}$ \\
\hline Organs received & $\begin{array}{l}\text { Stomach, SB, } \\
\text { liver }\end{array}$ & $\begin{array}{l}\text { Stomach, SB, } \\
\text { liver, colon }\end{array}$ & $\begin{array}{l}\text { Stomach, SB, } \\
\text { liver }\end{array}$ & $\begin{array}{l}\text { Stomach, SB, } \\
\text { liver }\end{array}$ & $\begin{array}{l}\text { Stomach, SB, } \\
\text { liver }\end{array}$ & SB & $\begin{array}{l}\text { Stomach, SB, } \\
\text { liver }\end{array}$ & $\begin{array}{l}\text { Stomach, SB, } \\
\text { liver }\end{array}$ \\
\hline Cold ischaemia time (h) & 9.6 & 8 & 6.3 & 10.6 & 9.2 & 6.9 & 9.7 & NA \\
\hline Follow up & $4.5 \mathrm{y}$ & $5 \mathrm{y}$ & $5 \mathrm{y}$ & $7 \mathrm{~m}$ & $2 \mathrm{~m}$ & $1 \mathrm{y}$ & $2.5 \mathrm{y}$ & $2 \mathrm{y}$ \\
\hline Postoperative problems & Bezoar & $\begin{array}{l}\text { Bezoar, urinary } \\
\text { tract infection }\end{array}$ & $\begin{array}{l}\text { Narcotic } \\
\text { withdrawal, } \\
\text { pancreatitis, } \\
\text { MBP }\end{array}$ & $\begin{array}{l}\text { Exfoliative } \\
\text { rejection }\end{array}$ & $\begin{array}{l}\text { Urinary tract } \\
\text { infection, } \\
\text { rejection }\end{array}$ & & $\begin{array}{l}\text { Achalasia, } \\
\text { narcotic } \\
\text { withdrawal }\end{array}$ & $\begin{array}{l}\text { Dumping } \\
\text { syndrome }\end{array}$ \\
\hline Outcome & Alive & Alive & $\begin{array}{l}\text { Died } 4 \text { y after } \\
\text { TX }\end{array}$ & $\begin{array}{l}\text { Died } 7 \mathrm{~m} \\
\text { after TX }\end{array}$ & $\begin{array}{l}\text { Died } 2 \mathrm{~m} \text { after } \\
\text { TX }\end{array}$ & Alive & Alive & Alive \\
\hline Ostomies & No & $\begin{array}{l}\text { G tube, } \\
\text { ileostomy }\end{array}$ & $\begin{array}{l}\text { G tube, } \\
\text { ileostomy }\end{array}$ & $\begin{array}{l}\text { G tube, } \\
\text { ileostomy }\end{array}$ & $\begin{array}{l}\text { G tube, J tube, } \\
\text { ileostomy }\end{array}$ & No & J tube, ileostomy & J tube, ileostomy \\
\hline School & Yes & Yes & Yes & & & & Yes & Yes \\
\hline Nutrition & Eating & Eating & $\begin{array}{l}\text { Eating/partial } \\
\text { enteral feeds }\end{array}$ & $\begin{array}{l}\text { Off TPN } \\
\text { until rejection }\end{array}$ & $\begin{array}{l}\text { Enteral feeds } \\
\text { at death }\end{array}$ & Eating & $\begin{array}{l}\text { Eating, J tube for } \\
\text { fluid replacement }\end{array}$ & $\begin{array}{l}\text { Eating, J tube for } \\
\text { fluid replacement }\end{array}$ \\
\hline
\end{tabular}




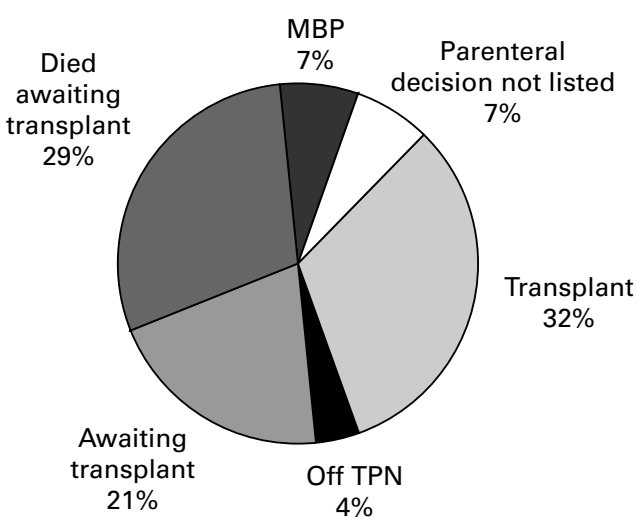

Figure 1 Outcome of children with the diagnosis of chronic intestinal pseudo-obstruction referred for intestinal transplantation. MBP, Munchausen syndrome by proxy; $T P N$, total parenteral nutrition.

months to 18 years) who underwent intestinal transplantation. Five suffered from neuropathic CIPO and did not have bladder disease. Three children suffered from hollow visceral myopathy, all with documented bladder involvement. All children were TPN dependent at transplant and had evidence of synthetic liver failure or history of repeated line infections. Table 2 summarises clinical characteristics, type of transplant performed, and outcomes. The excised bowel was inspected for histological features of neuropathy or myopathy using haematoxylin and eosin and acetylcholinesterase (AChE). Trichrome stain was also used in patients 4 and 5, suspected of having myopathy, in order to look for fibrosis. Finally, in patients 4,5 , and 6 , protein gene product 9.5 stain was applied. The surgical aspects of transplantation have been described elsewhere ${ }^{10}$; the immunosuppressive regimen and monitoring of rejection was the same as in other intestinal transplant recipients described previously. ${ }^{10} 12$

\section{Results}

Table 1 and fig 1 summarise the characteristics and outcome of the 27 patients referred for transplant evaluations; table 2 summarises

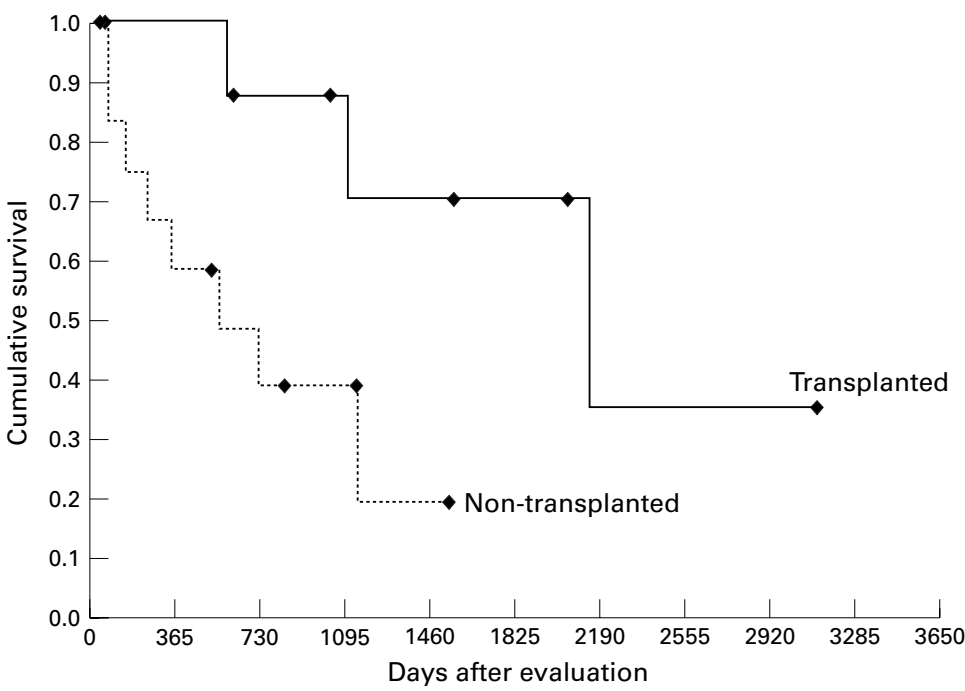

Figure 2 Fractional survival curves from the date of evaluation, comparing children who underwent transplantation with children who did not. those of the transplanted children. Figure 2 shows survival curves for patients transplanted and those evaluated but not transplanted.

Follow up of transplanted children ranged between two months and six years (median 2.6 years). Table 2 reports histology of nerves and muscle in the bowel removed during transplant. After transplant, all children could be weaned off TPN. Three children have died. One child expired two months after transplant after an overwhelming adenovirus infection. She was off TPN at the time of her death. Another child died seven months after transplantation due to exfoliative rejection of the intestine. He had been on full enteral feeding prior to the rejection episode. The third patient died four years after transplantation. She had been off TPN and on full oral feedings prior to succumbing to complications of pancreatitis. The other five are alive, off TPN, and able to eat by mouth. All patients have shown satisfactory linear growth except patient 7 who was 19 years old and had radiological evidence of fused epiphyseal lines at the time of transplant, and patient 5 who died two months after transplant.

Quality of life in these children was comparable to that of other intestinal transplant patients. ${ }^{13}$ Permanent placement of an endostomy was required in six children. All survivors live at home, and all school age children have returned to school at an age appropriate level; the median number of medications two years post-transplantation is four per day, most are administered twice a day. Sixty per cent of parents report spending less than an hour a day in administration of medications and stoma care.

Six of eight children developed rejection, a rate comparable to that of other intestinal transplant recipients. Most rejection episodes were mild except in one child (patient 4) who died after severe rejection. No patient developed chronic rejection. Epstein-Barr virus infection occurred in one child but resolved without development of post-transplant lymphoproliferative disease. Other postoperative problems included signs and symptoms of achalasia developing when an adolescent (patient 7) who had been on parenteral nutrition prior to transplantation began to eat. It is likely that the achalasia was present prior to transplantation and the lack of oral intake minimised the symptoms prior to surgery. She is now eating satisfactorily one year after pneumatic lower oesophageal sphincter dilatation, which followed two unsuccessful trials of botulinum toxin injections. Another child (patient 8) who had undergone a subtotal gastrectomy when she received an isolated small bowel transplant, developed dumping syndrome and is now doing well on a low carbohydrate, high fat diet.

All patients who received allograft stomachs have delayed gastric emptying and documented recurrent gastric bezoars. The bezoars were found on surveillance endoscopy and did not seem to affect the children clinically. Two patients suffered from severe neuropathic pain and required high doses of narcotics pre- and postoperatively. This led to complicated 
postoperative management requiring involvement of the pain team and psychiatric counselling. All three children with bladder involvement developed episodes of urinary tract infections postoperatively. Finally, in one child (patient 1), Munchausen syndrome by proxy was strongly suspected after transplantation, leading to a temporary separation of the child from the mother. In retrospect, the suspicion has arisen that the child had been victim of Munchausen syndrome by proxy even before the transplant and the preoperative diagnosis of pseudo-obstruction was questioned. ${ }^{14} \mathrm{Her}$ antroduodenal manometry, performed three years prior to transplantation, had shown the presence of motor migrating complexes during fasting and qualitative abnormalities suggestive of a mild neuropathic motor disease. Her symptoms had worsened dramatically in the months prior to the transplant. The resected bowel showed normal muscular layers, normal ganglion cells, and myenteric plexuses with thickened nerve fibres in the lamina propria on AChE staining.

\section{Discussion}

Intestinal transplantation has now emerged as a life saving option for patients with intestinal failure. ${ }^{10} 11$ The indications for intestinal transplantation in CIPO patients are the same as in other patients with intestinal failure: recurrent central venous infections, liver failure, and loss of central venous access. Because of the poor motility in CIPO causing significant bowel dilatation, these patients might even be at greater risk of bacterial overgrowth and subsequent bacterial translocation ${ }^{15} 16$ than other children with true short bowel syndrome.

Our data show that intestinal transplantation can be successfully performed in children with CIPO and it gives them the opportunity to be free from TPN. However, the preoperative evaluation, the operation itself, and the postoperative course in children with CIPO may be more complex than in other patients undergoing intestinal transplantation. While children with short bowel syndrome often have a functioning colon and stomach and only require isolated small intestinal transplantation, children with CIPO may need a multivisceral transplant with removal of organs such as the colon and creation of an endostomy.

There have previously been reports of patients with a diagnosis of CIPO who on further evaluation turned out to be victims of Munchausen syndrome by proxy, a psychiatric disorder where a parent over reports or produces illness in a child. ${ }^{17}{ }^{18}$ This was also our suspicion in two patients evaluated but not listed for transplantation and in one patient who underwent transplantation. In a patient with CIPO in whom the diagnosis is not supported by history and manometry is normal or only mildly abnormal, the possibility of Munchausen syndrome by proxy must be considered. We believe that it is important to perform motility studies of the entire gastrointestinal tract and thoroughly review the patient's past medical history prior to transplantation to confirm the diagnosis and deter- mine what type of graft should be used. Manometry has also been used to differentiate gut neuropathies from myopathies. ${ }^{5}$ This determination is particularly difficult when the bowel is dilated. It is also known that motor abnormalities may be identified in the gastrointestinal tract of children with a variety of functional bowel disorders and in children with inflammatory processes affecting the intestine. ${ }^{19}$ Caution should also be used to avoid over interpretation of motility studies performed in sedated children. In two children with manometry suggestive of myopathy, our laboratory could not identify any pathological abnormality. It is possible that other immunochemistry techniques such as using c-kit antibodies or electron microscopy, which were not used in our patients, could in the future clarify pathophysiological abnormalities in patients with CIPO.

We have previously shown that successful outcome after transplantation varies according to graft type. ${ }^{11}$ Patients who receive an isolated intestinal graft generally have a more benign postoperative course with fewer complications. However, we have seen a high incidence of graft failure due to rejection. We have observed that children receiving the larger "multivisceral" graft that includes the liver allograft develop rejection of the intestinal graft less often and the rejection episodes are generally milder. ${ }^{20}$ It has been postulated that transplanting the more tolerogenic lymphocytes present in the liver may lead to intestinal graft protection. ${ }^{20}$ So far, this observation has not been confirmed by other centres. Because bigger operations are fraught with a higher incidence of complications, a thorough assessment of the entire gastrointestinal tract is needed to identify the diseased organs needing replacement. Consequently, the surgical approach should be varied and tailored to each individual patient. It is notable that although stomach and colon composites of the allograft do not reject as often as the small intestinal component, they may present with unique infectious and ischaemic complications. ${ }^{21}$

Postoperatively, the management of children with CIPO differs from that of patients undergoing intestinal transplantation. Weaning patients from the high dose narcotics required to control their pain before transplant often requires a multidisciplinary approach. Urinary tract infections must be prevented by use of prophylactic antibiotics, creation of a vesicostomy, or intermittent catheterisation in children with bladder disease. When monitoring the graft for rejection, care needs to be taken to endoscope and biopsy the small bowel rather than any other organs transplanted because it seems to be preferentially involved in rejection. ${ }^{21}$

Quality of life in children receiving intestinal transplant for CIPO is comparable to that of children transplanted for other causes of intestinal failure. ${ }^{13}$ Small numbers and the lack of data accrued prospectively precludes comparison of quality of life in TPN dependent CIPO patients before and after transplantation. The cost of intestinal transplantation is considerable. At our institution the median cost of all 
intestinal transplantations that have been performed is estimated to be $\$ 350000$ including the first post-transplant year, while one year of TPN support costs about \$50-100 000 ( $£ 80-160000)$ per year.

Early referral of children with intestinal failure for transplantation is critical. Some CIPO patients dependent on TPN do not manifest any signs of liver disease nor experience recurrent line infections, ${ }^{22}$ but it is important to identify children with complications from TPN and refer them early. While survival of intestinal transplant recipients in the past has not been spectacular compared with other solid organ transplants, it may be the only chance of survival in children with intestinal failure suffering complications from TPN. Neuropathic forms of CIPO are more common than myopathic types, ${ }^{23}$ but myopathic CIPO seems to be associated with more severe involvement of gut motility. This observation is supported by the high number of children evaluated for transplantation who suffered from myopathic forms. We do not advocate transplantation in children with only mild liver enzyme elevations without evidence of liver synthetic abnormalities. Persistent coagulopathy (prothrombin time greater than 15 seconds), hyperbilirubinaemia $(>554 \mu \mathrm{mol} / \mathrm{l})$, and evidence of hypersplenism (such as a platelet count less than $100000 / \mathrm{ml}$ ), have been shown to be poor prognostic signs among patients referred to our institution for transplantation, with less than $30-40 \%$ one year survival without transplant. ${ }^{24}$ In this series, one third of the CIPO children referred died before suitable organs became available. In particular, all children with direct bilirubin greater than $150 \mu \mathrm{mol} / 1$ were either transplanted or died while waiting. Earlier referral might have increased the chance of finding a suitable organ. In view of the still high morbidity and mortality associated with intestinal transplantation it is also essential that optimal care be provided before the transplant. This includes careful management of parenteral nutrition to minimise the risk of associated cholestasis and scrupulous central line care to prevent line infections. ${ }^{22}$

In summary, intestinal transplantation is a possible life saving measure in children with CIPO. Early referral of children that are experiencing complications from TPN such as persistent evidence of liver injury, or recurrent line infections with loss of vascular access may improve the chances of a successful outcome.
1 Rudolph CD, Hyman PE, Altschuler SM, et al. Diagnosis and treatment of chronic intestinal pseudo-obstruction in children: report of consensus workshop. $\mathcal{F}$ Pediatr Gastroenterol Nutr 1997;24:102-12.

2 Vargas JH, Sachas P, Ament ME. Chronic intestinal pseudo-obstruction syndrome in pediatrics: results of a national survey by members of the North American Society of Gastroenterology and Nutrition. $\mathcal{F}$ Pediatr Gastroenterol Nutr 1989;7:323-32.

3 Sigurdsson L, Guze C, Hyman PE, et al. Children growing up with hollow visceral myopathy. I Pediatr Gastroenterol Nutr 1997;25:458.

4 Hyman PE, Di Lorenzo C, McAdams L, et al. Predicting the clinical response to cisapride in children with chronic intestinal pseudo-obstruction. Am f Gastroenterol 1993;88: $832-6$.

5 Cucchiara S, Annese V, Minella R, et al. Antroduodenojejunal manometry in the diagnosis of chronic idiopathic intesNutr 1994;18:294-305.

6 Boige N, Faure C, Cargil G, et al. Manometric evaluation in visceral neuropathies in children. $\mathcal{F}$ Pediatr Gastroenterol Nutr 1994;19:71-7.

7 Di Lorenzo C, Hyman PE. Gastrointestinal motility in neonatal and pediatric practice. Gastroenterol Clin North Am 1996;25:203-24

8 Forchielli ML, Young MC, Flores AF, et al. Immune deficiencies in chronic intestinal pseudo-obstruction. Acta Paediatr 1997;86:1077-81.

9 Di Lorenzo C, Flores AF, Buie T, et al. Intestinal motility and jejunal feedings in children with chronic intestinal pseudo-obstruction. Gastroenterology 1995;108:1379-85.

10 Kocoshis SA, Reyes J, Todo S, et al. Small intestinal transplantation for irreversible intestinal failure in children. Dig Dis Sci 1997;42:1997-2008.

11 Reyes J, Bueno J, Kocoshis SA, et al. Current status of intestinal transplantation in children. F Pediatr Surg 1998;33: 243-54.

12 Sigurdsson L, Reyes J, Putnam P, et al. Endoscopies in pediatric intestinal transplantation: five years experience. Am $\mathcal{F}$ Gastroenterol 1998;93:207-11.

13 Kosmach B. Pediatric small bowel transplantation: an innovated strategy for short gut syndrome. Critical Care Nurse (in press).

14 Kosmach B, Tarbell S, Reyes J, et al. "Munchausen by proxy" syndrome in a small bowel transplant recipient. Transplant Proc 1996;28:2790-1.

15 Huseby E, Skar V, Hoverstad T, et al. Intensity of the migrating motor complex (MMC) predicts colonization with Gram negative bacilli in proximal small intestine. Gut 1993;34:525.

16 Huseby E, Skar, Iversen T, et al. The relationship between patterns of motility and Gram negative bacilli in proximal small intestine of patients with late radiation enteropathy. $\mathcal{f}$ Gastrointest Motil 1993;5:196.

17 Baron HI, Beck DC, Vargas M, et al. Overinterpretation of gastrodudenal motility studies: two cases involving Munchausen syndrome by proxy. F Pediatr 1995;126:397-400.

chausen syndrome by proxy. F Pediatr 1995;126:397-400.
18 Hyman PE. Chronic intestinal pseudo-obstruction. In: Hyman PE, Di Lorenzo C, eds. Pediatric gastrointestinal motility disorders. New York: Academy Professional Informational Services, Inc., 1994:115-28.

19 Hyman PE, Napolitano J, Diego A, et al. Antroduodenal manometry in the evaluation of chronic functional gastrointestinal symptoms. Pediatrics 199;86:39-44.

20 Abu-Elmagd K, Reyes J, Todo S, et al. Clinical intestinal transplantation: new perspectives and immunological considerations. F Am Coll Surg 1998;186:512-25.

21 Sigurdsson L, Reyes J, Todo S, et al. Anatomical variability of rejection in intestinal allografts following pediatric intes-
tinal transplantation. $\mathcal{F}$ Pediatr Gastroenterol Nutr 1998;27: 403-6.

22 Moukarzel AA, Haddad I, Ament ME, et al. 230 patient years of experience with home long-term parenteral nutrition in childhood: natural history and life of

23 Mousa H, Cocjin J, Flores AF, et al. Multicenter experience with congenital intestinal pseudo-obstruction in children. $\mathcal{F}$ Pediatr Gastroenterol Nutr 1998;26:558.

24 Bueno J, Ohwada, S, Kocoshis SA, et al. Factors impacting on the survival of children with intestinal failure referred for intestinal transplantation. F Pediatr Surg 1999;34:27-33. 